\title{
Bisphenol A Removal by Adsorption Using Waste Biomass: Isotherm and Kinetic Studies
}

\author{
Zainab Mat Lazim ${ }^{1, *}$, Salmiati ${ }^{1,2}$, Tony Hadibarata ${ }^{3, *}$ (i) , Zulkifli Yusop ${ }^{1,2}$, Tasnia Hassan Nazifa ${ }^{4}$, Noorul

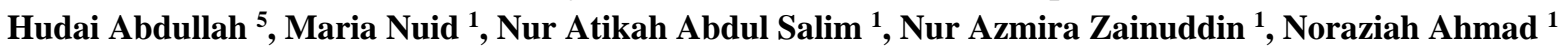 \\ 1 School of Civil Engineering, Faculty of Engineering, Universiti Teknologi Malaysia, 81310 UTM Johor, Malaysia \\ 2 Centre for Environmental Sustainability and Water Security (IPASA), Research Institute for Sustainable Environment \\ (RISE), Universiti Teknologi Malaysia, 81310 Skudai, Johor, Malaysia \\ 3 Department of Environmental Engineering, Faculty of Engineering and Science, Curtin University, 98009 Miri, Sarawak, \\ Malaysia \\ 4 Knowledge Management and Innovation, Water, Sanitation \& Hygiene (WASH), BRAC, Dhaka 1212, Bangladesh \\ 5 Centre for Diploma Studies, Faculty of Civil Engineering, Universiti Tun Hussein Onn Malaysia, 84600 Muar, Johor, \\ Malaysia \\ * Correspondence: hadibarata@curtin.edu.my; zaienab88@yahoo.com;
}

Scopus Author ID 16233109100

Received: 2.07.2020; Revised: 24.07.2020; Accepted: 25.07.2020; Published: 28.07.2020

\begin{abstract}
BPA is categorized as a new emerging pollutant that mimics the structure and function of hormone estrogen for humans and animals. The removal of BPA had been concerned because human exposure toward BPA is widespread, and it is harmful to humans and the ecosystem. The aim of the study was to remove BPA by adsorption technique and understand the application of agricultural waste material as potential adsorbent. The increasing of the surface area of post-adsorption from $4.80 \mathrm{~m}^{2} / \mathrm{g}$ to $5.83 \mathrm{~m}^{2} / \mathrm{g}$ indicated that the sulphuric acid treatment responsible for the growth in the porosity of the banana bunches, increase the number of available binding sites and its ion-adsorption capacity. The highest removal of BPA by the banana bunch and coconut bunch was obtained in the following condition: the temperature at $25^{\circ}, \mathrm{pH} 3$, dosage at $100 \mathrm{mg}$, and agitation at $150 \mathrm{rpm}$. The adsorption process was well described with the Langmuir isotherm, while the best correlation with the kinetic study of BPA adsorption was the pseudo-second-order model. The negative values of $\Delta \mathrm{H}^{\circ}$ suggested that the adsorption of BPA onto banana bunch $\left(-13.748 \mathrm{~J} \mathrm{~mol}^{-1}\right)$ and coconut bunch $\left(-5693.67 \mathrm{~J} \mathrm{~mol}^{-1}\right)$ is exothermic in nature.
\end{abstract}

Keywords: bisphenol A; banana bunch; coconut bunch; isotherms; pseudo-second-order kinetics.

Nomenclature: $\mathrm{C}_{0}$ - Initial BPA concentration in the liquid phase $(\mathrm{mg} / \mathrm{L}) ; \mathrm{C}_{\mathrm{e}}$ - Equilibrium of BPA concentration in the liquid phase $(\mathrm{mg} / \mathrm{L}) ; \mathrm{C}_{\mathrm{t}}-\mathrm{BPA}$ concentration at time $\mathrm{t}$ in the liquid phase $(\mathrm{mg} / \mathrm{L})$; $\mathrm{V}$ - Solution volume (L); M - Mass of the dry adsorbent $(\mathrm{g}) ; q_{e}$ - The amount of sorbed BPA at equilibrium (mg/g); $q_{e}$ - The amount of sorbed BPA at time $\mathrm{t}(\mathrm{mg} / \mathrm{g}) ; \mathrm{Q}_{\max }$ - Maximum sorption capacity in Langmuir model $(\mathrm{mg} / \mathrm{g}) ; K_{\mathrm{L}}$ - Langmuir constant $(\mathrm{L} / \mathrm{mg}) ; K_{\mathrm{F}}$ - Freundlich constants associated with adsoprtion capacity; $\mathrm{n}$ - number of isotherm parameters; A - Temkin equilibrium binding constant $(\mathrm{L} / \mathrm{g})$; B - Temkin constant related to the heat of sorption $\left(\mathrm{J} \mathrm{mol}^{-18}\right) ; \mathrm{K}_{1}$ - Pseudo-first-order rate constant; $\mathrm{K}_{2}$ - Pseudo-second order rate constant; $K_{c}$ - Concentration factor of a chemical equilibrium equation; R Natural gas constant $\left(\mathrm{m}^{3} \cdot \mathrm{atm} \cdot \mathrm{K}^{-1} \cdot \mathrm{mol}^{-1}\right)$.

(C) 2020 by the authors. This article is an open-access article distributed under the terms and conditions of the Creative Commons Attribution (CC BY) license (https://creativecommons.org/licenses/by/4.0/).

\section{Introduction}

BPA stands for bisphenol A that first discovered in the 1890s and industrialized to produce strong plastics and resins since the 1960s. Currently, BPA is categorized as a new emerging pollutant that mimics the structure and function of hormone estrogen for humans and 
animals [1]. It is persistently being used in consumer goods and containers that store food and beverages, such as water bottles [2,3]. The removal of BPA had been concerned because human exposure toward BPA is widespread, and it is harmful to humans and the ecosystem. Exposure of BPA can cause a possible health effect on the brain and prostate of infants and children $[1,4]$. The abundance uses of BPA had led to the emission of toxicity of BPA into a water source and affect the aquatic life and contaminate the drinking water. BPA can enter the body through ingestion; especially, then, it will interfere with human hormonal function. The previous study revealed that BPA was detected at a dangerous level in the urine sample of children and adults [3]. For this study, the adsorption treatment had been proposed to eliminate the BPA in aqueous solution. This technique is commonly known as a cheap and efficient method, good removal ability, insensitivity, and simple design. For the removal of emerging pollutants by adsorption technique, commonly activated carbon (AC) was used as adsorbent [5-7]. However, currently, adsorbent from agricultural waste is most preferred and used widely compared to commercial activated carbon. Agricultural waste has been widely investigated as low-cost adsorbent since it is known to contain a variety of functional groups and basic components which have potential sorption capacities for several pollutants, other than environmentally friendly and reliable resources [8-11].

For this study, banana bunch and coconut bunch were used as adsorbent and treated with acid sulfuric for chemical modification. The agricultural waste came from different kinds of shape, color, and sources; thus, it needs pre-treatment before use as adsorbent. All colors, metals, and any soluble organic compounds of adsorbent ought to remove with different kinds of modifying agents, such as oxidizing agents, organic compounds, acid and base solutions, dyes, and mineral [12]. The objective of the study was to remove BPA by adsorption technique and understand the application of agricultural waste material as potential adsorbent. Various parameters condition on the adsorption and removal of BPA were also investigated.

\section{Materials and Methods}

\subsection{Sorbate and chemicals.}

BPA $\left(\mathrm{C}_{15} \mathrm{H}_{16} \mathrm{O}_{2}\right.$, molecular weight $=228.29, \lambda_{\max }=278 \mathrm{~nm}$; purity $97 \%$ of SigmaAldrich Milwaukee, USA) was used as sorbates in this study. The stock solution of BPA was prepared by dissolving it (20 ppm) into $1 \mathrm{~L}$ distilled water. Figure 1 shows the molecular structure of BPA. Sulfuric acid (95-97\%) was purchased from Merck (Germany). Ethanol $(96 \%)$ and other chemicals were purchased from Qrec (New Zealand).

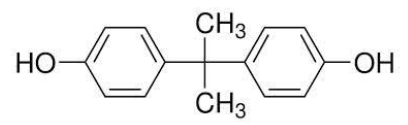

Figure 1. Molecular structure of BPA.

\subsection{The sorbent.}

Banana bunch (Musa acuminate) and coconut bunch (Cocos nucifera) were selected as the sorbent for the adsorption of BPA after selection. The sorbents were washed, cut (30 mesh sieve), oven-dried $\left(105^{\circ} \mathrm{C}\right)$, and pulverized before activation. The biomass was activated with $\mathrm{H}_{2} \mathrm{SO}_{4}$ in ratio 1:1 (sorbent: acid) [13]. The dried adsorbent was washed with distilled water 
until the $\mathrm{pH}$ becomes neutral. The treated sorbents and stored in an airtight container for subsequent use.

\subsection{Batch experiment.}

Sorption experiments were accomplished by agitating (150rpm) $100 \mathrm{mg}$ of adsorbent with $20 \mathrm{ppm}$ od BPA solution $(\mathrm{pH} \mathrm{3})$ at room temperature. The blank experiment was performed by preparing a solution without adsorbent to ensure that no BPA was adsorbed onto the flask, which would interfere during spectrophotometer analysis. The various conditions were implemented to know the effect of some parameters in the sorption of BPA, as summarized in Table 1.

Table 1. Summarizes for all experiments of batch adsorption.

\begin{tabular}{l|c|c|c|c} 
Parameters & $\begin{array}{c}\text { Initial } \\
\mathrm{pH}\end{array}$ & Dosage $(\mathrm{mg})$ & Temperature $\left({ }^{\circ} \mathrm{C}\right)$ & $\begin{array}{c}\text { Agitation } \\
(\mathrm{rpm})\end{array}$ \\
\hline Effect of Initial $\mathrm{pH}$ & $3-9$ & 100 & 25 & 150 \\
\hline Effect of Dosage & 3 & $50-500$ & 25 & 150 \\
\hline Effect of Temperature & 3 & 100 & $25-60$ & 150 \\
\hline Effect of Agitation & 3 & 100 & 25 & $50-250$
\end{tabular}

After a specific time interval, adsorbents were separated by filtration utilizing Whatman filter paper $(125 \mathrm{~mm})$ No 1 , and the initial and residual BPA concentration were determined using a (NANOCOLOR® VIS, Macherey-Nagel, Germany) at $278 \mathrm{~nm}$. All experiments were performed in triplicate. The amount of BPA adsorbed onto banana bunch and coconut bunch at time $\mathrm{t}, q_{t}(\mathrm{mg} / \mathrm{g})$, and at equilibrium time $q_{e}(\mathrm{mg} / \mathrm{g})$ was calculated by equation (1), (2), and (3), respectively.

$$
\begin{aligned}
& \mathrm{R}(\%)=\frac{C_{o}-C_{e}}{C_{o}} \times 100 \\
& q_{t}=\frac{\left(C_{o}-C_{t}\right) V}{M} \\
& q_{e}=\frac{\left(C_{o}-C_{e}\right) V}{M}
\end{aligned}
$$

\subsection{Sorption isotherm model.}

In this study, the Langmuir, Freundlich, and Temkin models were used to examine the sorption behavior of BPA onto the adsorbent, as calculated by equation (4), (5), (6), respectively.

$$
\begin{aligned}
& q_{e}=\frac{Q_{\max } K_{L} C_{e}}{1+K_{L} C_{e}} \\
& q_{e}=K_{F} C_{e}{ }^{1 / n} \\
& q_{e}=B \ln A+B \ln C_{e}
\end{aligned}
$$

\subsection{Sorption kinetic model.}

In this study, the pseudo-first-order, pseudo-second order], and intraparticle diffusion models were applied to observe the adsorption rates of BPA onto the adsorbent, as calculated by equation (7), (8), and (9), respectively [14]. 


$$
\begin{aligned}
& \text { In }\left(q_{e}-q_{t}\right)=\operatorname{In} q_{e}-k_{l} t \\
& \frac{t}{q_{t}}=\frac{1}{k_{2} q_{e}{ }^{2}}+\frac{t}{q_{e}} \\
& q_{t}=k_{\text {diff }} t^{1 / 2}+C
\end{aligned}
$$

\subsection{Thermodynamic Study.}

The thermodynamic studies were carried out at different temperature conditions, and calculated parameters included enthalpy $(\Delta H)$ and entropy $(\Delta S)$, as calculated by the following equation [15].

$$
\begin{aligned}
& \ln K_{c}=\frac{\Delta S^{\circ}}{R}-\frac{\Delta H^{\circ}}{R T} \\
& K_{c}=\frac{C_{e(\text { adsorben })}}{C_{e(\text { solution })}}
\end{aligned}
$$

\subsection{SEM and FTIR.}

Morphological and surface functional group characteristics of the Banana bunch (Musa acuminate) and coconut bunch (Cocos nucifera) before and after adsorption were carried out using Scanning electron microscopy (JOEL-633F-SEM, Japan) and Fourier transform infrared (FTIR) spectroscopy (Spectrum one, Perkin Elmer, USA), respectively. The adsorbents were then characterized by FESEM, FTIR, and BET for before and after treatment of sulphuric acid.

\section{Results and Discussion}

\subsection{SEM, BET, and FTIR analysis.}

Morphological characterization of the banana bunch and coconut bunch using SEM, before and after activation, is shown in Figure 2 and Figure 3. Prior to activation, the banana bunch showed more pore of different sizes and surface areas that actively react with BPA. The BET showed that the surface area of post-activation was increased from $4.80 \mathrm{~m}^{2} / \mathrm{g}$ to $5.83 \mathrm{~m}^{2} / \mathrm{g}$, respectively.



Figure 2. Field Emission Scanning Electron Microscope (FESEM) image of the banana bunch: raw (A) and after activation (B). 
This result indicated that the sulphuric acid treatment responsible for the growth in the porosity of the banana bunches, increase the number of available binding sites and its ionadsorption capacity [16-18]. The post-activation morphology of the coconut bunch revealed a rough surface morphology indicating that the pore had been filled with BPA molecule, which implies a strong interaction between BPA and coconut bunch. However, the BET showed the depleting of surface area from $3.8 \mathrm{~m}^{2} / \mathrm{g}$ to $2.2 \mathrm{~m}^{2} / \mathrm{g}$. The previous study showed that the pore volume, pore size distribution, functional groups of the contaminants, surface area, surface chemistry of adsorbent, and the solution characteristics played a significant role in the effectiveness of adsorbent to eliminate the sorbates $[9,19,20]$.

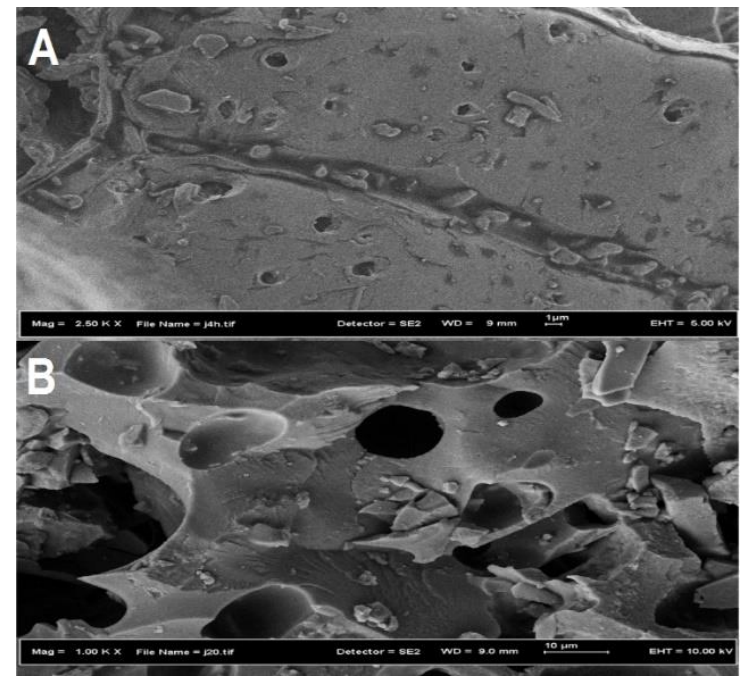

Figure 3. Field Emission Scanning Electron Microscope (FESEM) image of coconut bunch: raw (A) and after activation (B).

FTIR spectra of the banana bunch and coconut bunch before and after adsorption are shown in Figure 4 and Figure 5. From Fig. 4, it has seen the broad peak at $3405.54 \mathrm{~cm}^{-1}$, which indicated the involvement of hydroxyl groups, which possibly present in lignin, hemicellulose, and cellulose of the banana bunch. The oscillations of the $\mathrm{N}-\mathrm{H}$ and $\mathrm{O}-\mathrm{H}$ functional groups can be seen at the wavelength of $3405 \mathrm{~cm}^{-1}$ and $2922 \mathrm{~cm}^{-1}$. Structure group of $\mathrm{CH}, \mathrm{CH}_{2}$, and $\mathrm{CH}_{3}$ contain in banana bunch also causes stretching of $\mathrm{C}-\mathrm{H}$ which proved by a peak appeared at a wavelength of $2097 \mathrm{~cm}^{-1}, 2922 \mathrm{~cm}^{-1}$, and the weak bands at $2920 \mathrm{~cm}^{-1}$ while a peak that showed at a wavelength of $1618 \mathrm{~cm}^{-1}$ indicated as $\mathrm{C}=\mathrm{C}$ bonds in aromatic rings bending mode of the absorbed water. The peak showing at $1489 \mathrm{~cm}^{-1}$ and $1244 \mathrm{~cm}^{-1}$ known as the $\mathrm{C}-\mathrm{O}$ carboxyl bands that indicated the activity of carboxyl oxygen atoms occurred. Besides, the figure showed $\mathrm{CH}_{2}$ bends, $\mathrm{OH}$ bends, and $\mathrm{C}-\mathrm{O}$ skeletal vibrations at the bands of 1489,1384 , and $1313 \mathrm{~cm}^{-1}$, respectively. While, $\mathrm{C}-\mathrm{O}$ is stretching in hemicellulose at the band of 1244 $\mathrm{cm}^{-1}$.

This result also showed the presence of silica as bending peaks at $1143 \mathrm{~cm}^{-1}$, and 1032 $\mathrm{cm}^{-1}$ indicated the $\mathrm{Si}-\mathrm{O}$ stretching. The result of FTIR for the treated banana bunch showed an overlapped bands of sulphonic acid hydroxyl and free phenolic and alcoholic hydroxyl groups of the banana bunch $\left(3400 \mathrm{~cm}^{-1}\right)$. Besides, the presence of $\mathrm{SO}_{3} \mathrm{H}$ groups was definite by the peaks shifting at $1143 \mathrm{~cm}^{-1}\left(\mathrm{SO}_{2}\right)$ and $1032 \mathrm{~cm}^{-1}\left(\mathrm{SO}_{2}\right)$. The presence of carboxylic acid groups also was confirmed by peak shifting at bands of $1695 \mathrm{~cm}^{-1}$ (C O) and $1620 \mathrm{~cm}^{-1}$ (C O) [16]. FTIR spectrum of coconut bunch showed the possible involvement of the hydroxyl group as band shifting around the broad peak at $3406.36 \mathrm{~cm}^{-1}$. The functional group of $\mathrm{CH}$, $\mathrm{CH}_{2}$, and $\mathrm{CH}_{3}$ contain in coconut bunch also causes stretching of $\mathrm{C}-\mathrm{H}$, which proved by a peak 
appeared at bands of $2924 \mathrm{~cm}^{-1}$. The vibrations of the $\mathrm{N}-\mathrm{H}$ and $\mathrm{O}-\mathrm{H}$ functional groups can be seen at the wavelength of $3406 \mathrm{~cm}^{-1}$ and $2118 \mathrm{~cm}^{-1}$. The peaks at $1731 \mathrm{~cm}^{-1}$ and $1248 \mathrm{~cm}^{-1}$ indicated as $\mathrm{C}=\mathrm{C}$ bonds in aromatic rings which also known as absorption band. The peak showing at $1603 \mathrm{~cm}^{-1}$ and $1052 \mathrm{~cm}^{-1}$, known as the $\mathrm{C}-\mathrm{O}$ carboxyl bands that indicated the activity of carboxyl oxygen atoms occurred.

A

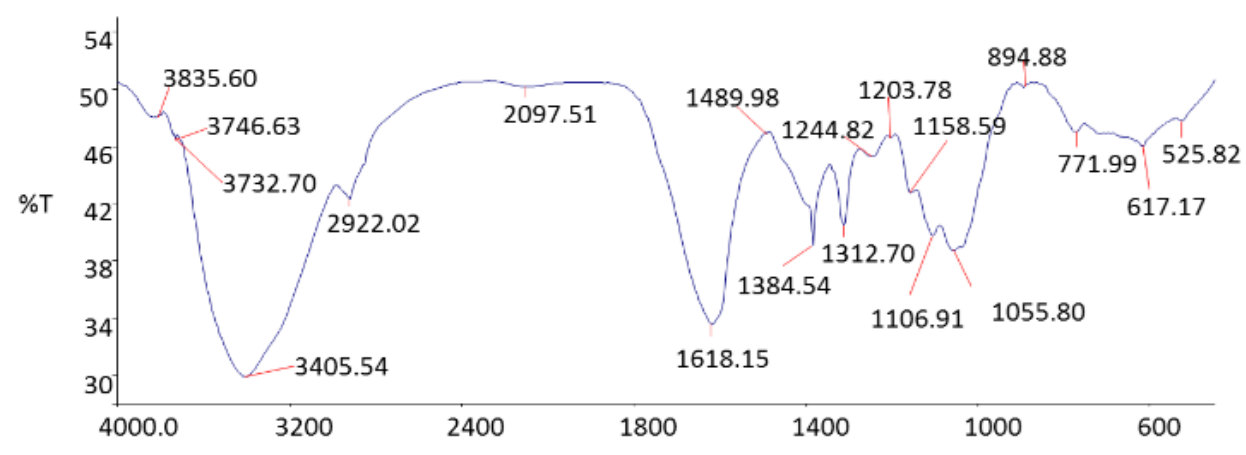

B
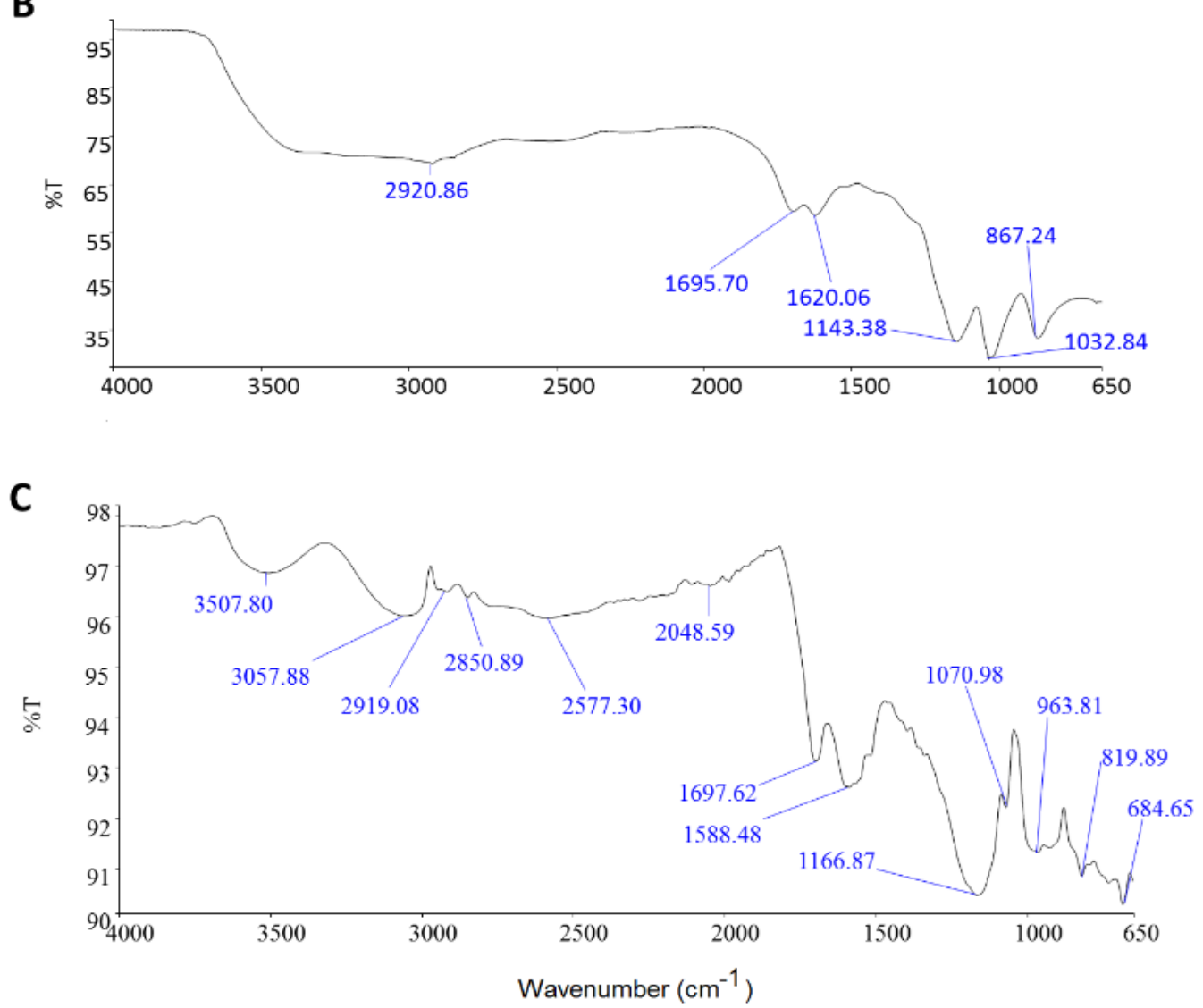

Figure 4. FTIR spectrum of the raw banana bunch (A) and banana bunch after pre-treatment (B) and the banana bunch after sorption $(\mathrm{C})$.

This result also showed the presence of silica as bending peaks at $1139 \mathrm{~cm}^{-1}$, and 1031 $\mathrm{cm}^{-1}$ indicated the $\mathrm{Si}-\mathrm{O}$ stretching band. The efficiency of the banana bunch and coconut bunch treatment is shown on the dominance of wavenumbers in inorganic groups. The presence of some functional groups and absorption peak in the adsorbent indicated the complex nature of the adsorbent from banana and coconut bunch. An increase and decrease in intensity of the peak occur to observe the role of the functional group of adsorbents in sorbates bonding. It was revealed that carbon and oxygen in the form of carboxylic acid was the most dominant element 
in the adsorption mechanism. The presence of a sulfur element during chemical activation was also the main factor in increasing the elimination of contaminants [21,22].
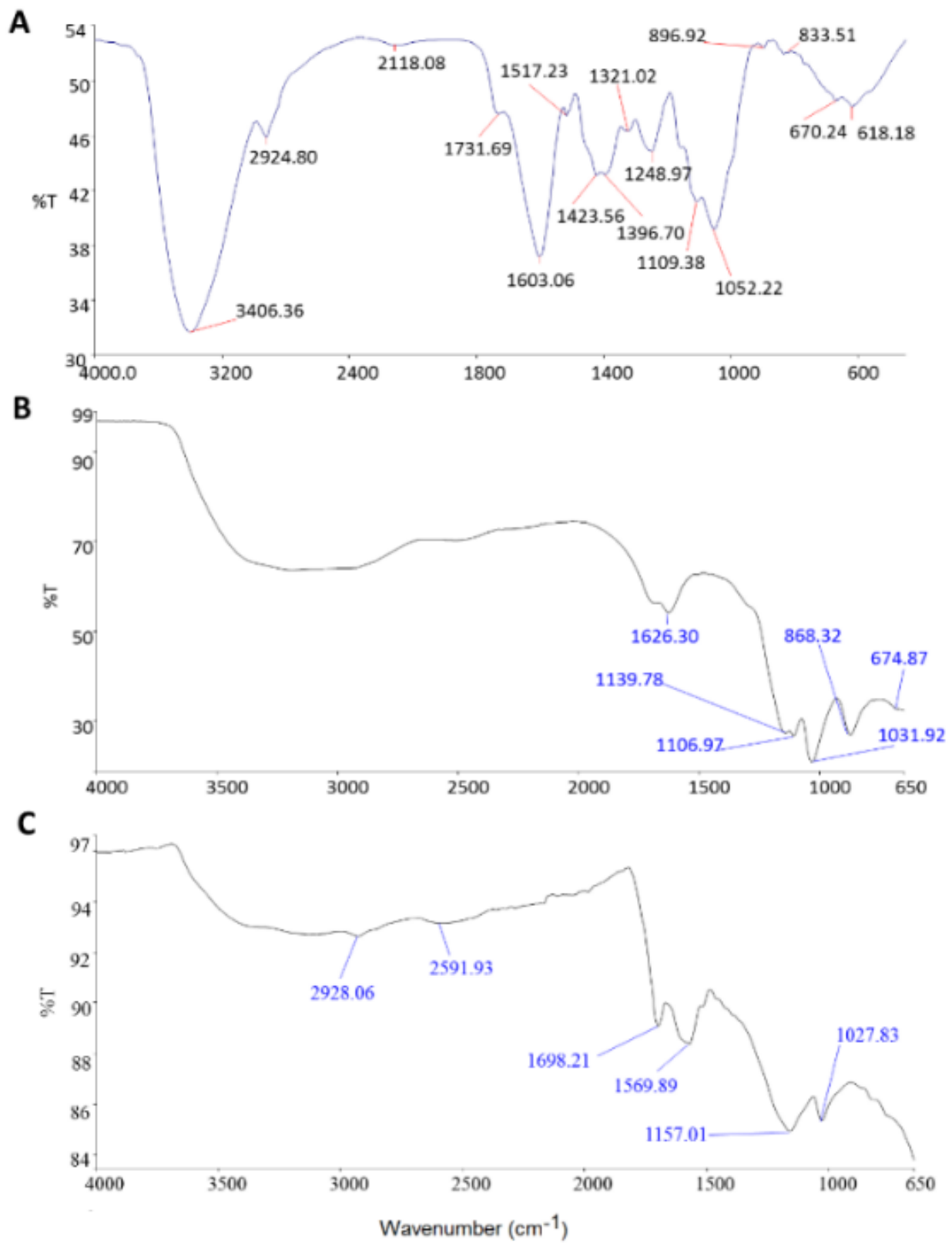

Figure 5. FTIR spectrum of raw coconut bunch (A) and coconut bunch after pre-treatment (B) and the coconut bunch after sorption $(\mathrm{C})$.

\subsection{Batch studies.}

Table 2 revealed the effect of parameters on the adsorption of BPA by the banana bunch and coconut bunch. The highest removal of BPA by the banana bunch and coconut bunch was obtained in the following condition: the temperature at $25^{\circ}(75.53$ and $77.70 \%)$, $\mathrm{pH} 3(74.57$ and $77.39 \%)$, dosage at $100 \mathrm{mg}(75.53$ and $77.71 \%)$, and agitation at $150 \mathrm{rpm}$ (76.77 and $77.12 \%$ ). Previous studies reported that low $\mathrm{pH}$ value influenced the ionic state of the solution, thus increasing the adsorption process. Alkaline condition stimulates the electrostatic repulsion between BPA and the adsorbent, and changing the surface area of adsorbent becomes negative and inclined the binding affinity [23-26]. Thus, the optimum adsorbent dosage for this experiment was $100 \mathrm{mg}$ indicating an advantage for economic purposes due to the usage of a 
low quantity of adsorbent to reach high sorption of BPA [27, 28]. The adsorption was not impacted by agitation since there is no pattern of speed in increasing the BPA removal. In this case, moderate agitation $(150 \mathrm{rpm})$ resulting in the highest removal sorption of BPA.

Table 2. Effect of Parameters on the adsorption of BPA.

\begin{tabular}{|c|c|c|c|}
\hline \multirow{2}{*}{\multicolumn{2}{|c|}{ Parameters }} & \multicolumn{2}{|c|}{ Adsorbents } \\
\hline & & \multirow{2}{*}{$\begin{array}{l}\text { Banana Bunch (\%) } \\
75.53 \\
\end{array}$} & \multirow{2}{*}{$\begin{array}{l}\text { Coconut Bunch (\%) } \\
77.70\end{array}$} \\
\hline Temperature $\left({ }^{0} \mathrm{C}\right)$ & 25 & & \\
\hline & 30 & 72.42 & 74.91 \\
\hline & 40 & 62.80 & 69.32 \\
\hline & 50 & 55.03 & 64.66 \\
\hline & 60 & 41.06 & 61.24 \\
\hline \multirow[t]{4}{*}{$\mathrm{pH}$} & 3 & 74.57 & 77.39 \\
\hline & 5 & 73.66 & 76.45 \\
\hline & 7 & 72.11 & 75.22 \\
\hline & 9 & 69.94 & 72.42 \\
\hline \multirow[t]{4}{*}{ Adsorbent Dosage (mg) } & 50 & 69.32 & 55.65 \\
\hline & 100 & 75.53 & 77.71 \\
\hline & 300 & 60.93 & 66.52 \\
\hline & 500 & 49.13 & 64.65 \\
\hline \multirow[t]{5}{*}{ Agitation (rpm) } & 50 & 73.35 & 64.69 \\
\hline & 100 & 75.84 & 52.90 \\
\hline & 150 & 76.77 & 77.12 \\
\hline & 200 & 75.53 & 60.23 \\
\hline & 250 & 73.98 & 72.34 \\
\hline
\end{tabular}

\subsection{Sorption isotherm model.}

Table 3. Effect of initial concentration on BPA adsorption onto banana bunch and coconut bunch.

\begin{tabular}{l|l|l|l|l}
\multirow{2}{*}{$C_{\mathbf{o}}$} & \multicolumn{2}{|c|}{ Removal $(\boldsymbol{\%})$} & \multicolumn{2}{c}{$\mathbf{q e}(\mathbf{m g} / \mathbf{g})$} \\
\cline { 2 - 5 } & Banana bunch & Coconut bunch & Banana bunch & Coconut bunch \\
\hline 5 & 48.81 & 53.78 & 0.73 & 0.81 \\
\hline 10 & 68.81 & 59.5 & 2.06 & 1.79 \\
\hline 20 & 86.27 & 86.58 & 5.18 & 5.20 \\
\hline 40 & 91.42 & 90.65 & 10.98 & 10.88 \\
\hline 60 & 85.59 & 89.01 & 15.41 & 16.02 \\
\hline 80 & 81.58 & 81.73 & 19.58 & 19.62 \\
\hline 100 & 69.92 & 72.4 & 20.98 & 21.72
\end{tabular}

In order to evaluate the removal of BPA in aqueous solution and to understand its movement during the adsorption process, the sorption behavior and mechanism of BPA should be disclosed. The information about the equilibrium stage through the isotherm model is very important to know the relationship between adsorbent and sorbate. Table 3 reveals an increase in the equilibrium sorption capacity of the banana bunch (Musa acuminate) and coconut bunch (Cocos nucifera) with increasing initial BPA concentration. This current study showed that, at the initial stages, the adsorption capacity $\left(\mathrm{q}_{\mathrm{e}}\right)$ was rapidly increased and then gradually decreased after the optimum rate. This was suggested due to the ability of adsorbent per unit mass in adsorbing the accumulation of BPA. Therefore, the adsorption capacity of adsorbent was influenced by the initial concentration of BPA [29, 30]. As the concentration was increased from 5 to $100 \mathrm{mg} / \mathrm{L}$, the adsorption capacity of BPA was also increased. This was due to the higher probability of collision between adsorbent particles and BPA ions. The higher initial concentration of BPA enhanced the adsorption capacity since the driving force was higher at the initial stage to overcome all mass transfer resistances of the BPA between the adsorbent and adsorbate [31-33]. While, for the removal rate of BPA, when the BPA concentration increased from 5 to $40 \mathrm{mg} / \mathrm{L}$, the percentage removal was increased, while, when the initial concentration increased from $60-100 \mathrm{mg} / \mathrm{L}$, the percentage removal decreased. 

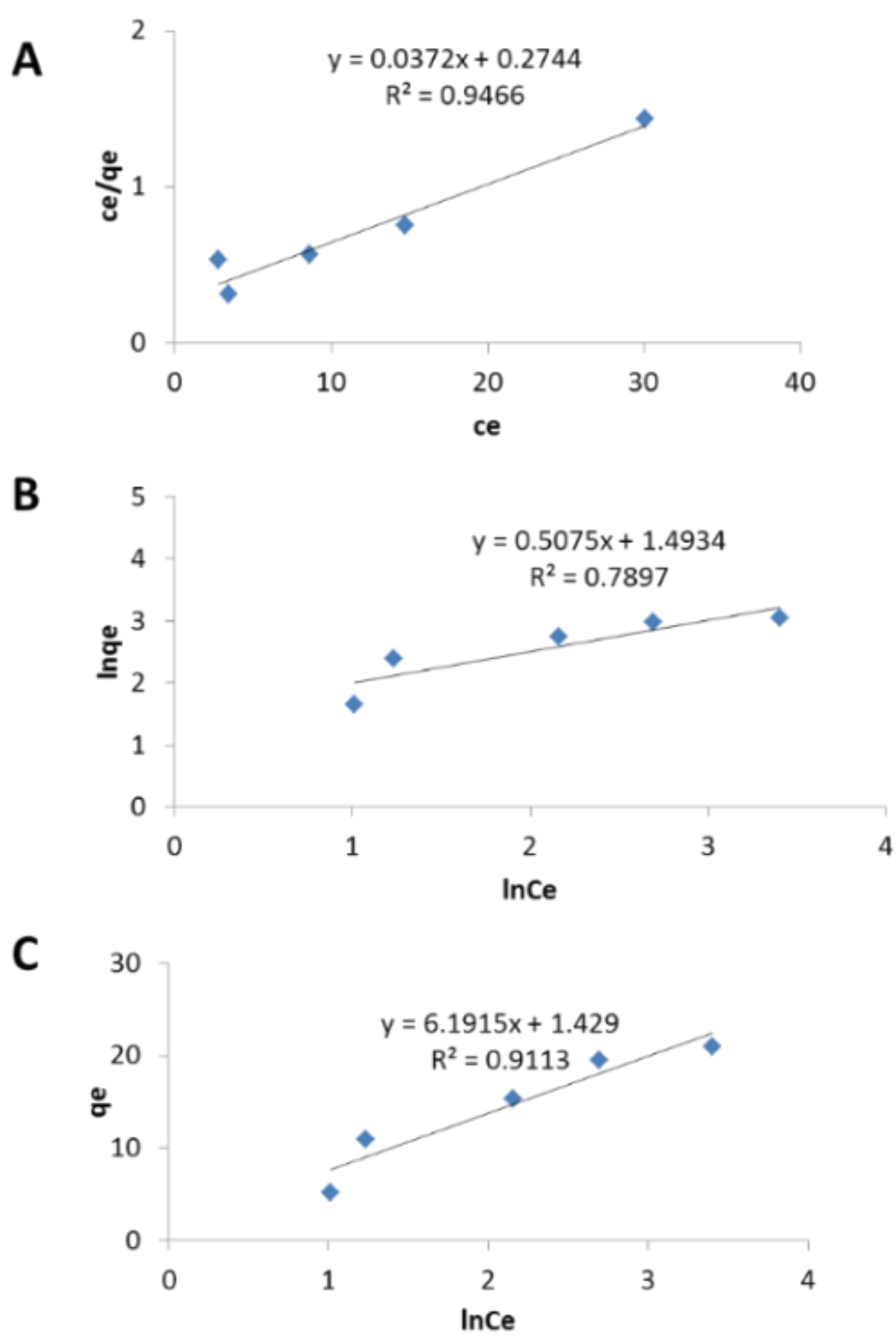

Figure 6. Adsorption isotherm of banana bunch; Langmuir (A), Freundlich (B) and Temkin (C).

Hence, the removal rate of BPA was dependent on the total available sorption sites of adsorbent, which were relatively limited and then resulting in a drop in the percentage removal of BPA when all the active sites were fully occupied [5, 34]. In this section, Langmuir, Freundlich, and Temkin were chosen as the most commonly used models for evaluating the experimentally acquired adsorption isotherms (Figures 6 and Figure 7). The values of the model parameters and the isotherm error deviation data for those model equations determined by linear regression analysis. The highest $\mathrm{R}^{2}$ for adsorption of BPA by was shown by the banana bunch, and the coconut bunch is Langmuir (0.947 and 0.934), indicating the monolayer coverage of pollutant molecule onto a solid surface. This model also reveals that once the active adsorbent site is completely filled with the adsorbate, the adsorption process would stop at that site [35-37]. However, the Langmuir adsorption model is only capable of explaining the adsorption capability and equilibrium process and not capable of determining the adsorption mechanism. [36,38]. 

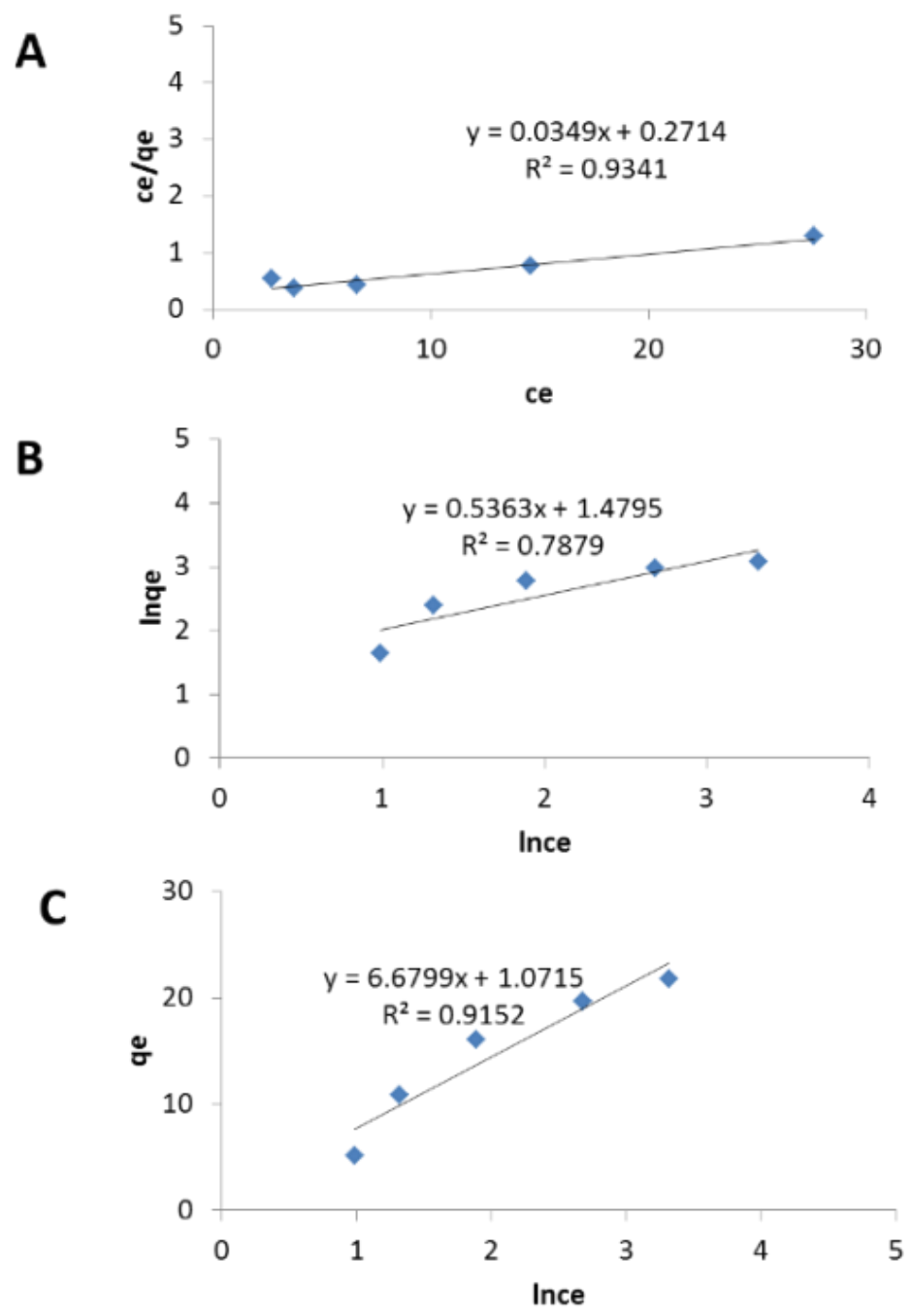

Figure 7. Adsorption isotherm of coconut bunch; Langmuir (A), Freundlich (B), and Temkin (C).

\subsection{Sorption kinetic model.}

Investigation of the kinetic model is an important part of the adsorption process because it provides information about the reaction pathway and rate-controlling mechanism of the reaction. Table 4 shows the influence of the contact time on the BPA adsorption onto the banana bunch (Musa acuminate) and coconut bunch (Cocos nucifera).

Table 4. Effect of contact time on BPA adsorption onto banana bunch and coconut bunch.

\begin{tabular}{lllll}
\hline Time $(\mathrm{min})$ & Removal $(\%)$ & & $\mathrm{qe}(\mathrm{mg} / \mathrm{g})$ & \\
\cline { 2 - 5 } & Banana bunch & Coconut bunch & Banana bunch & Coconut bunch \\
\hline 2 & 59.38 & 70.29 & 3.563 & 4.215 \\
4 & 64.66 & 72.11 & 3.880 & 4.327 \\
6 & 65.9 & 74.91 & 3.954 & 4.494 \\
8 & 66.21 & 75.53 & 3.973 & 4.532 \\
10 & 67.14 & 75.84 & 4.029 & 4.550 \\
18 & 70.9 & 75.84 & 4.252 & 4.550 \\
21 & 72.42 & 76.15 & 4.345 & 4.569 \\
24 & 75.53 & 77.7 & 4.532 & 4.662 \\
30 & 75.22 & 77.4 & 4.513 & 4.643 \\
36 & 75.22 & 76.7 & 4.513 & 4.606 \\
38 & 74.91 & 76.68 & 4.494 & 4.588 \\
\hline
\end{tabular}

Both banana and coconut bunch adsorbents showed that the optimum adsorption equilibrium was reached at the time of $24^{\text {th }}$ min with the percentage removal and adsorption 
capacity of BPA were $75.53 \%, 4.53 \mathrm{mg} / \mathrm{g}$, and $77.7 \%, 4.66 \mathrm{mg} / \mathrm{g}$ respectively. The outcomes show that the removal rate and adsorption capacity increase gradually over time because, in the early stages of adsorption, there are a lot of empty sites and spread around the surface and easy to access, the impact of chemical activation on adsorbents so that absorption runs quickly in the beginning [26,39]. After equilibrium, the active adsorbent site was saturated with the sorbates causing the stagnancy of removal rate and adsorption capacity after they reach the highest value $[5,40,41]$. The results were also similar to some studies that, In the early phase of the adsorption process, the concentration of pollutants dissolved in the aqueous solution was very high, while the empty and active pore were dispersed on the surface of the adsorbent. Thus the removal rate and sorption capacity were rapidly increased. However, with increasing contact time, the number of active pores on the surface of the adsorbent was decreased, resulting in the decrease of adsorption of sorbates [29,42].
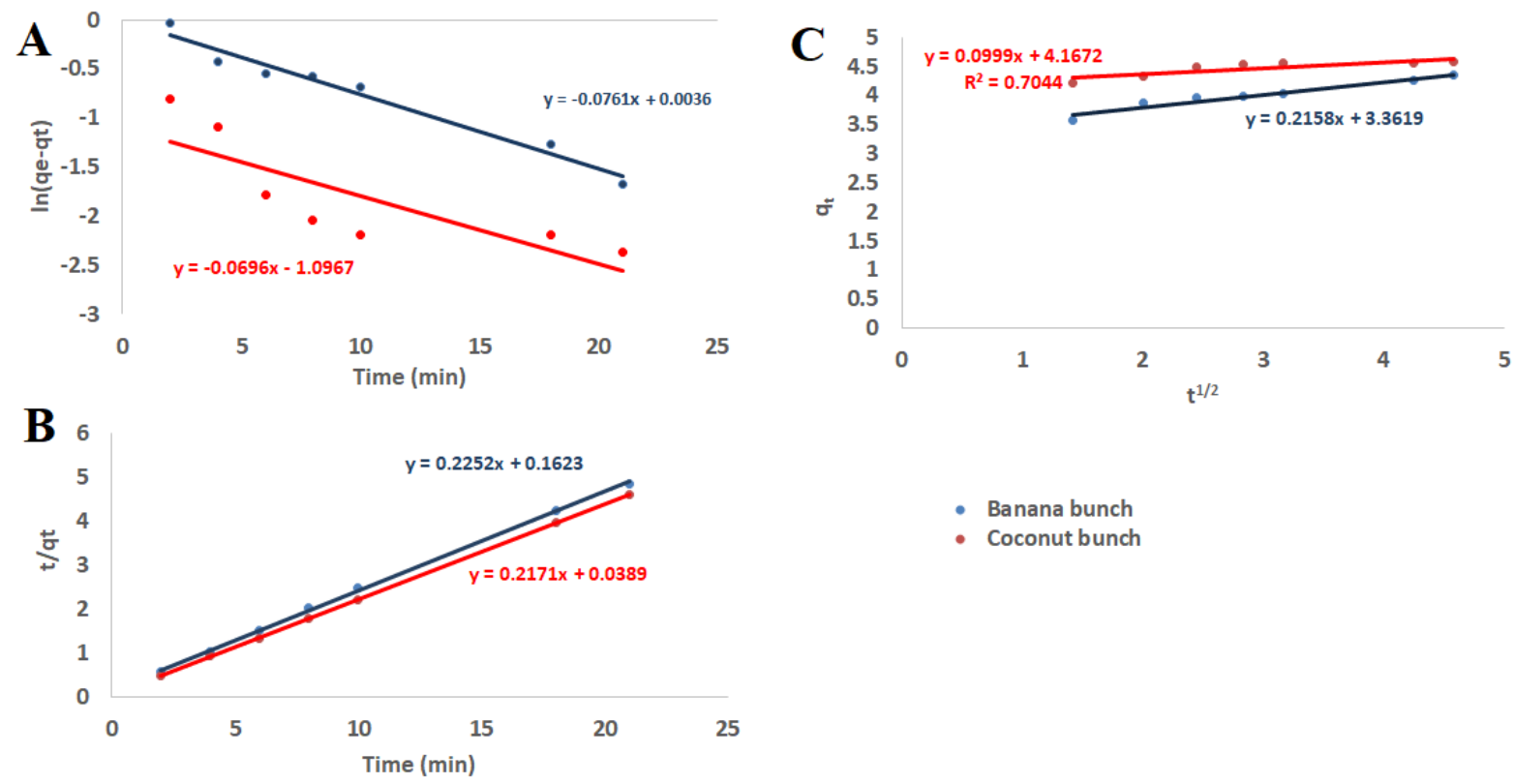

Figure 8. Adsorption kinetics plots for BPA using: (A) Pseudo-first order, (B) Pseudo-second order, and (C) intra-particle diffusion model.

Table 5. Adsorption capacity, isotherm and kinetic for BPA adsorption on different materials.

\begin{tabular}{|c|c|c|c|c|}
\hline Adsorbent & Isotherm models & Kinetic Model & $q_{e}(\mathrm{mg} / \mathrm{g})$ & References \\
\hline Rice husk ash & Freundlich, Tempkin & Pseudo-second order & 8.72 & [44] \\
\hline $\begin{array}{l}\text { Commercial granular } \\
\text { activated carbon }\end{array}$ & Freundlich, Tempkin & Pseudo-second order & 3.54 & [44] \\
\hline $\begin{array}{l}\text { Empty fruit bunch } \\
\text { activated carbon }\end{array}$ & Langmuir & Pseudo-second order & 41.98 & {$[45]$} \\
\hline $\begin{array}{l}\text { Surfactant-modified } \\
\text { natural zeolite }\end{array}$ & Tempkin & Pseudo-second order & 6.9 & [46] \\
\hline Banana bunch & Langmuir & Pseudo-second order & 4.53 & This study \\
\hline coconut & Langmuir & Pseudo-second order & 4.66 & This study \\
\hline
\end{tabular}

The Adsorption kinetics plots for BPA using Pseudo-first order, Pseudo -second order, and intra-particle diffusion model was shown in Figure 8. This study showed that the $\mathrm{R}^{2}$ value for the pseudo-second-order model was found to be higher than that of the pseudo-first-order model and intraparticle diffusion model. The highest $\mathrm{q}_{\mathrm{e}}$ of the pseudo-second-order was closer to the adsorption of BPA at equilibrium $(4.5$ and $4.7 \mathrm{mg} / \mathrm{g}$ ) than the value of another kinetic model. Even though the $\mathrm{R}^{2}$ values of both models showed a good correlation, as it can be seen from the high $\mathrm{R}^{2}$ values of 0.97 (the pseudo-first-order model) and 0.94 (intraparticle diffusion), respectively. In most reports focusing on BPA removal, the pseudo-second-order 
fitted best to the kinetic adsorption data, as shown in Table 5. Thus, the adsorbents proposed that the overall rate of the BPA adsorption mechanism was chemisorption. This chemisorption mechanism involves the valence force of chemical bonds via electron exchange between the adsorbent and the pollutants [5,24,43].

\subsection{Adsorption thermodynamics.}

It is commonly known that the adsorption mechanism is strongly influenced by temperature, and these processes are controlled by thermodynamic parameters such as the standard enthalpy change $\left(\Delta \mathrm{H}^{0}, \mathrm{~J} \mathrm{~mol}^{-1}\right)$, the standard entropy change $\left(\Delta \mathrm{S}^{0}, \mathrm{~J} \mathrm{~mol}^{-1} \mathrm{~K}^{-1}\right)$ and the standard free Gibbs energy change $\left(\Delta \mathrm{G} 0, \mathrm{~J} \mathrm{~mol}^{-1}\right)$ of the adsorption processes. The values of $\Delta S^{\circ}$ and $\Delta H^{\circ}$ were calculated from the intercept and slope of the plot between $\ln K_{\mathrm{c}} \mathrm{Vs}$ $1 / T$ for BPA concentration of $20 \mathrm{mg} / \mathrm{L}$ (Fig. 9). The negative values of $\Delta \mathrm{H}^{\circ}$ suggested that the adsorption of BPA onto banana bunch (-13.748 $\left.\mathrm{J} \mathrm{mol}^{-1}\right)$ and coconut bunch $\left(-5693.67 \mathrm{~J} \mathrm{~mol}^{-1}\right)$ is exothermic in nature. Furthermore, the reduction of strong sorptive forces among the active sites in the adsorbent surface might cause a negative value of $\Delta \mathrm{H}^{\circ}[24,30,33]$. The standard entropy change $\left(\Delta S^{o}\right)$ shows the negative value for a banana bunch $\left(-19.84 \mathrm{~J} \mathrm{~K}^{-1} \mathrm{~mol}^{-1}\right)$ due to the decrease of randomness at the solid-solution interface at the time of adsorption of BPA from water body [30,33]. On the contrary, the coconut bunch shows the positive value $(7.053$ $\mathrm{J} \mathrm{K}^{-1} \mathrm{~mol}^{-1}$ ) due to the affinity of adsorbent in BPA removal and randomness at the solution interface during adsorption [30,33,47].

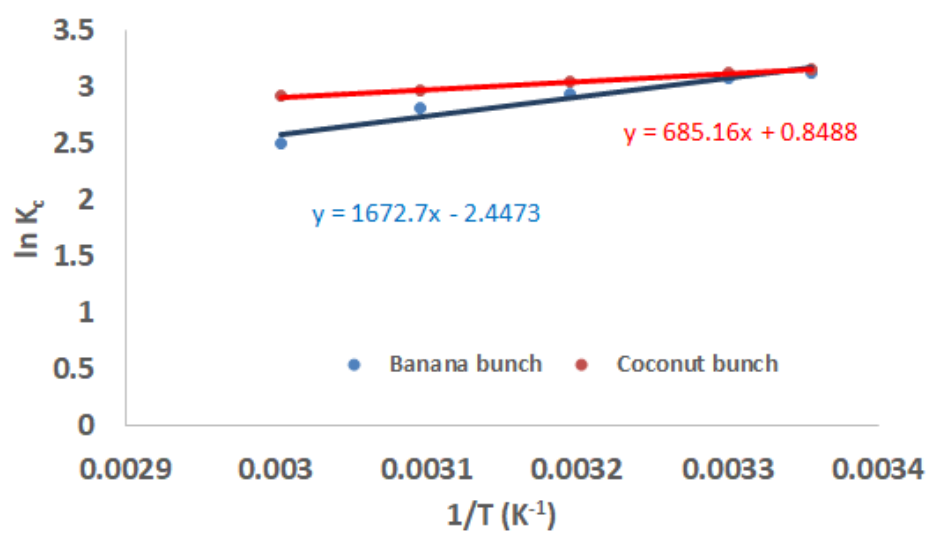

Figure 9. Thermodynamic adsorption of BPA by a banana bunch and coconut bunch.

\section{Conclusions}

The potential adsorbent derived from the banana bunch and coconut bunch were studied for BPA removal in aqueous solution. The highest removal of BPA by the banana bunch and coconut bunch was obtained in the following condition: the temperature at $25^{\circ}, \mathrm{pH} 3$, dosage at $100 \mathrm{mg}$, and agitation at $150 \mathrm{rpm}$. Alkaline condition stimulates the electrostatic repulsion between BPA and the adsorbent, and changing the surface area of adsorbent becomes negative and inclined the binding affinity. The highest $\mathrm{R}^{2}$ for adsorption of BPA was shown by the banana bunch, and the coconut bunch is Langmuir (0.947 and 0.934), indicating the monolayer coverage of adsorbate molecule onto a solid surface. The adsorption of BPA at equilibrium $\left(\mathrm{q}_{\mathrm{e}}\right)$ for banana bunch was $4.53 \mathrm{mg} / \mathrm{g}$, which is almost the same as the calculated value for the pseudo-second-order model, which is $4.50 \mathrm{mg} / \mathrm{g}$. While the $\mathrm{R}^{2}$ in the pseudo-second-order model gives a value of 0.99 that indicated a better fit, which is a little bit higher than the pseudo- 
first-order and intraparticle diffusion with $\mathrm{R}^{2}$ value, it was 0.97 and 0.94 . Thus, the adsorbents proposed that the overall rate of the BPA adsorption mechanism was chemisorption.

\section{Funding}

The authors would like to acknowledge the Universiti Teknologi Malaysia and Ministry of Education Malaysia for providing the Long-Term Research Grant Scheme 4L810 - (Grant No. 203/PKT/6720006) and Q.J130000.2522.19H06. The authors also appreciate UTM Zamalah for providing a scholarship in favor of the undertaken project.

\section{Acknowledgments}

\section{This research has no acknowledgment.}

\section{Conflicts of Interest}

The authors declare no conflict of interest.

\section{References}

1. Kessler, J.; Dawley, D.; Crow, D.; Garmany, R.; Georgel, P. Potential Health Risks Linked to Emerging Contaminants in Major Rivers and Treated Waters. Water 2019, 11, https://doi.org/10.3390/w11122615.

2. Almeida, S.; Raposo, A.; Almeida-Gonzalez, M.; Carrascosa, C. Bisphenol A: Food Exposure and Impact on Human Health. Comprehensive Reviews in Food Science and Food Safety 2018, https://doi.org/10.1111/1541-4337.12388.

3. Inadera, H. Neurological Effects of Bisphenol A and its Analogues. International Journal of Medical Sciences 2015, 12, 926-936, https://doi.org/10.7150/ijms.13267.

4. Metz, C.M. Bisphenol A. Workplace Health \& Safety 2016, 64, 28-36, https://doi.org/10.1177/2165079915623790.

5. Lazim, Z.M.; Hadibarata, T.; Puteh, M.H.; Yusop, Z. Adsorption Characteristics of Bisphenol A onto LowCost Modified Phyto-Waste Material in Aqueous Solution. Water, Air, \& Soil Pollution 2015, 226, https://doi.org/10.1007/s11270-015-2318-5.

6. Zhou, X.; Wei, J.; Liu, K.; Liu, N.; Zhou, B. Adsorption of Bisphenol A Based on Synergy between Hydrogen Bonding and Hydrophobic Interaction. Langmuir 2014, 30, 13861-13868, https://doi.org/10.1021/la502816m.

7. Jeirani, Z.; Niu, C.; Soltan, J. Adsorption of emerging pollutants on activated carbon. Reviews in Chemical Engineering 2016, https://doi.org/10.1515/revce-2016-0027.

8. Omo-Okoro, P.; Daso, A. P.; Okonkwo, O. A review of the application of agricultural wastes as precursor materials for the adsorption of per- and polyfluoroalkyl substances: A focus on current approaches and methodologies. Environmental Technology \& Innovation 2017, https://doi.org/10.1016/j.eti.2017.11.005.

9. Sabino, D.G.; Giusy L.; Mariangela, G.; Michele, N. Characteristics and adsorption capacities of low-cost sorbents for wastewater treatment: A review. Sustainable Materials and Technologies 2016, 9, 10-40, https://doi.org/10.1016/j.susmat.2016.06.002.

10. Inyinbor, A.A.; Oluyori, A.P.; Adelani-Akande, T.A. Biomass Valorization: Agricultural Waste in Environmental Protection, Phytomedicine and Biofuel Production. Biomass Volume Estimation and Valorization for Energy 2017, https://doi.org/10.5772/66102.

11. Dai, Y.; Sun, Q.; Wang, W.; Lu, L.; Liu, M.; Li, J.; Yang, S.; Sun, Y.; Zhang, K.; Xu, J.; Zheng, W.; Hu, Z.; Yang, Y.; Gao, Y.; Chen, Y.; Zhang, X.; Gao, F.; Zhang, Y. Utilizations of agricultural waste as adsorbent for the removal of contaminants: A review. Chemosphere 2018, 211, 235-253, https://doi.org/10.1016/j.chemosphere.2018.06.179.

12. Hokkanen, S.; Bhatnagar, A.; Sillanpa, M. A review on modification methods to cellulose-based adsorbents to improve adsorption capacity. Water Research 2016, 91, 156-173, https://doi.org/10.1016/j.watres.2016.01.008.

13. Lazim, Z.M.; Hadibarata, T.; Puteh, M.; Yusop, Z.; Wirasnita, R.; Mohd N.N. Utilization of durian peel as potential adsorbent for bisphenol a removal in aquoeus solution. Jurnal Teknologi 2015, 74, 109-115, https://doi.org/10.11113/jt.v74.4879.

14. Jean-Pierre, S. On the comparison of pseudo-first order and pseudo-second order rate laws in the modeling of adsorption kinetics. Journal Chemical Engineering 2016, 300, 254-263, https://doi.org/10.1016/j.cej.2016.04.079 
15. Lima, E.; Hosseini-Bandegharaei, A.; Moreno-Pirajajn, J.; Anastopoulos, I. A critical review of the estimation of the thermodynamic parameters on adsorption equilibria. Wrong use of equilibrium constant in the Van't Hoof equation for calculation of thermodynamic parameters of adsorption. Journal of Molecular Liquids 2018, https://doi.org/10.1016/j.molliq.2018.10.048.

16. Amode, J.O.; Santos, J.H.; Md. Alam, Z.; Mirza, A.H.; Mei, C.C. Adsorption of methylene blue from aqueous solution using untreated and treated (Metroxylon spp.) waste adsorbent: equilibrium and kinetics studies. International Journal of Industrial Chemistry 2016, 7, 333-345, https://doi.org/10.1007/s40090016-0085-9.

17. Akpomie, K.G.; Dawodu, F.A. Acid-modified montmorillonite for sorption of heavy metals from automobile effluent. Beni-Suef University. Journal of Basic and Applied Sciences 2016, 5, 1-12, https://doi.org/10.1016/j.bjbas.2016.01.003.

18. Ranaweera K.H.; Godakumbura P.I.; Perera B.A. Adsorptive removal of Co(II) in aqueous solutions using clearing nut seed powder. Heliyon 2020, 6, https://doi.org/10.1016/j.heliyon.2020.e03684.

19. Schwantes, D.; Gonçalves Jr, A.; Coelho, G.F.; Campagnolo, M.; Dragunski, D.; Tarley, C.; Miola, A.; Leismann, E. Chemical Modifications of Cassava Peel as Adsorbent Material for Metals Ions from Wastewater. Journal of Chemistry 2016, 2016, 1-15, https://doi.org/10.1155/2016/3694174.

20. Kuang, Y.; Zhang, X.; Zhou, S. Adsorption of Methylene Blue in Water onto Activated Carbon by Surfactant Modification. Water 2020, 12, https://doi.org/10.3390/w12020587.

21. Glover, T.G.; Peterson, G.W.; DeCoste, J.B.; Browe, M.A. Adsorption of Ammonia by Sulfuric Acid Treated Zirconium Hydroxide. Langmuir 2012, 28, 10478-10487, https://doi.org/10.1021/la302118h.

22. Jaouadi, M.; Hbaieb, S.; Guedidi, H.; Reinert, L.; Amdouni, N.; Duclaux, L. Preparation and characterization of carbons from $\beta$-cyclodextrin dehydration and from olive pomace activation and their application for boron adsorption. Journal of Saudi Chemical Society 2017, 21, 822-829, https://doi.org/10.1016/j.jscs.2016.01.001.

23. Li, Q.; Pan, F.; Li, W.; Li, D.; Xu, H.; Xia, D.; Li, A. Enhanced Adsorption of Bisphenol A from Aqueous Solution with 2-Vinylpyridine Functionalized Magnetic Nanoparticles. Polymers 2018, 10.

24. Wang, J.; Zhang, M. Adsorption Characteristics and Mechanism of Bisphenol A by Magnetic Biochar. International Journal of Environmental Research and Public Health 2020, 17, https://doi.org/10.3390/ijerph17031075.

25. John, Y.; David, V.E.; Mmereki, D. A Comparative Study on Removal of Hazardous Anions from Water by Adsorption: A Review. International Journal of Chemical Engineering 2018, 2018, 21-21, https://doi.org/10.1155/2018/3975948.

26. Banerjee, S.; Chattopadhyaya, M.C. Adsorption characteristics for the removal of a toxic dye, tartrazine from aqueous solutions by a low cost agricultural by-product. Arabian Journal of Chemistry 2017, 10, S1629S1638, https://doi.org/10.1016/j.arabjc.2013.06.005.

27. Didaskalou, C.; Buyuktiryaki, S.; Kecili, R.; Fonte, C.P.; Szekely, G. Valorisation of agricultural waste with an adsorption/nanofiltration hybrid process: from materials to sustainable process design. Green Chemistry 2017, 19, 3116-3125, https://doi.org/10.1039/c7gc00912g.

28. Furlan, F.L.; Filho, N.C.; Consolin, M.F.B.; Goncalves, M.S.; Valderrama, P.; Genena, A.K. Use of agricultural and agroindustrial residues as alternative adsorbents of manganese and iron in aqueous solution. Ambiente e Agua - An Interdisciplinary Journal of Applied Science 2018, 13, https://doi.org/10.4136/ambiagua.2181.

29. Rahmat, N.A.; Hadibarata, T.; Yuniarto, A.; Elshikh, M.S.; Syafiuddin, A. Isotherm and kinetics studies for the adsorption of bisphenol A from aqueous solution by activated carbon of Musa acuminata. IOP Conference Series: Materials Science and Engineering 2019, 495, https://doi.org/10.1088/1757899x/495/1/012059.

30. Mphahlele, K.; Onyango, M.S.; Mhlanga, S.D. Kinetics, Equilibrium, and Thermodynamics of the Sorption of Bisphenol A onto N-CNTs- $\beta$-Cyclodextrin and Fe/N-CNTs- $\beta$-Cyclodextrin Nanocomposites. Journal of Nanomaterials 2015, 2015, 1-13, https://doi.org/10.1155/2015/214327.

31. Nuengmatcha, P.; Chanthai, S. Thermodynamic and Kinetic Study of the Intrinsic Adsorption Capacity of Graphene Oxide for Malachite Green Removal from Aqueous Solution. Oriental Journal of Chemistry 2014, 30, https://doi.org/10.13005/ojc/300403.

32. Dehghani, M. H.; Ghadermazi, M.; Bhatnagar, A.; Sadighara, P.; Jahed-Khaniki, G.; Heibati, B.; McKay, G. Adsorptive removal of endocrine disrupting bisphenol A from aqueous solution using chitosan. Journal of Environmental Chemical Engineering 2016, 4, 2647-2655, https://doi.org/10.1016/j.jece.2016.05.011.

33. Phatthanakittiphong, T.; Seo, G. Characteristic Evaluation of Graphene Oxide for Bisphenol A Adsorption in Aqueous Solution. Nanomaterials 2016, 6, https://doi.org/10.3390/nano6070128.

34. Bhatnagar, A.; Anastopoulos, I. Adsorptive removal of bisphenol A (BPA) from aqueous solution: A review. Chemosphere 2017, 168, 885-902, https://doi.org/10.1016/j.chemosphere.2016.10.121.

35. Ayawei, N.; Ebelegi, A.N.; Wankasi, D. Modelling and Interpretation of Adsorption Isotherms. Journal of Chemistry 2017, 2017, 1-11, https://doi.org/10.1155/2017/3039817.

36. Togue Kamga, F. Modeling adsorption mechanism of paraquat onto Ayous (Triplochiton scleroxylon) wood sawdust. Applied Water Science 2018, 9, https://doi.org/10.1007/s13201-018-0879-3. 
37. Kumar, V.; Srinivas, G.; Wood, B.; Ramisetty, K.; Stewart, A.; Howard, C.; Brett, D.J.L.; RodriguezReinoso, F. Characterization of adsorption site energies and heterogeneous surfaces of porous materials. Journal of Materials Chemistry 2019, 7, https://doi.org/10.1039/C9TA00287A.

38. Chen, X. Modeling of Experimental Adsorption Isotherm Data. Information 2015, 6, 14-22, https://doi.org/10.3390/info6010014.

39. Pathania, D.; Sharma, S.; Singh, P. Removal of methylene blue by adsorption onto activated carbon developed from Ficus carica bast. Arabian Journal of Chemistry 2017, 10, https://doi.org/10.1016/j.arabjc.2013.04.021.

40. Fraga, T.J.M.; Carvalho, M.N.; Ghislandi, M.G.; Motta Sobrinho, M.A. Functionalized Graphene-Based Materials as Innovative Adsorbents of Organic Pollutants: A Concise Overview. Brazilian Journal of Chemical Engineering 2019, 36, 1-31, https://doi.org/10.1590/0104-6632.20190361s20180283.

41. Frezzini, M. A.; Massimi, L.; Astolfi, M. L.; Canepari, S.; Giuliano, A. Food Waste Materials as Low-Cost Adsorbents for the Removal of Volatile Organic Compounds from Wastewater. Materials 2019, 12, https://doi.org/10.3390/ma12244242.

42. Jain, S.; Ghosh, M. Effective removal of Bisphenol A from plastic waste leachates by microbial polymer impregnated with activated carbon. International Journal of Environmental Science and Technology 2019, https://doi.org/10.1007/s13762-019-02452-X.

43. Liu, L.; Deng, G.; Shi, X. Adsorption characteristics and mechanism of p-nitrophenol by pine sawdust biochar samples produced at different pyrolysis temperatures. Scientific Reports 2020, 10, https://doi.org/10.1038/s41598-020-62059-y.

44. Sudhakar, P.; Mall, I. D.; Srivastava, V. C. Adsorptive removal of bisphenol-A by rice husk ash and granular activated carbonda comparative study. Desalination and Water Treatment 2016, 57, 12375-12384, https://doi.org/10.1080/19443994.2015.1050700.

45. Wirasnita, R.; Hadibarata, T.; Yusoff, A. R. M.; Yusop, Z. Removal of Bisphenol A from Aqueous Solution by Activated Carbon Derived from Oil Palm Empty Fruit Bunch. Water Air and Soil Pollution 2014, 225, 2148, https://doi.org/10.1007/s11270-014-2148-x.

46. Genc, N.; Kilicoglu, O.; Narci, A. O. Removal of Bisphenol A aqueous solution using surfactant-modified natural zeolite: taguchi's experimental design, adsorption kinetic, equilibrium and thermodynamic study. Environmental Technology 2017, 38, 424-432, https://doi.org/10.1080/21622515.2016.1196739.

47. Batool, F.; Akbar, J.; Iqbal, S.; Noreen, S.; Bukhari, S.N.A. Study of Isothermal, Kinetic, and Thermodynamic Parameters for Adsorption of Cadmium: An Overview of Linear and Nonlinear Approach and Error Analysis. Bioinorganic Chemistry and Applications 2018, 2018, 1-11, https://doi.org/10.1155/2018/3463724. 